Article

\title{
The Spatiotemporal Pattern of Rainy-Season Precipitation in the Haihe River Basin, North China
}

\author{
Jun Guo ${ }^{1,2}$, Guoyu Ren ${ }^{1,3, * \mathbb{C}}$, Mingming Xiong ${ }^{2}$ and He Huang ${ }^{2}$ \\ 1 Department of Atmospheric Science, School of Environmental Studies, China University of Geosciences, \\ Wuhan 430074, China \\ 2 Tianjin Climate Center, Tianjin 300074, China \\ 3 Laboratory for Climate Studies, National Climate Center, CMA, Beijing 100081, China \\ * Correspondence: guoyoo@cma.gov.cn
}

Received: 21 April 2019; Accepted: 6 May 2019; Published: 20 August 2019

\begin{abstract}
The Haihe River basin of North China is characterized by extremely low per capita water resources and a consistently long-term decreasing trend of precipitation and runoff over the last few decades. This study analyzes the climatological features of rainy season (May-September) precipitation in the Haihe River basin and its branch systems based on a high-density hourly observational dataset during 2007-2017. We show that there are two high-rainfall zones in the basin, with one along the south of the Yanshan Mountains to Taihang Mountains and another along the Tuma River in the south. Rainstorm centers exist amidst the two zones. July generally sees the highest precipitation, followed by August, and May has the lowest precipitation. The major flood season is reached between the third pentad of July and the fourth pentad of August. The precipitation is high at night but low in the daytime. In the pre-flood season before early July, rainfalls mostly arrive at 16:00-21:00 $\mathrm{h}$. After entering the major flood season, the diurnal precipitation has two peaks, one at 17:00-22:00 $\mathrm{h}$ and the other at 0:00-7:00 $\mathrm{h}$. In the post-flood season after mid-August, the most rain occurs at night, with the peak appearing at 0:00-8:00 $\mathrm{h}$. The short-duration precipitation is mainly distributed in the mountainous areas, and the long-duration precipitation that contributes most to seasonal rainfalls appears in the plain areas, and the continuous precipitation mostly occurs in the windward slopes of the Taihang Mountains and the Yanshan Mountains. In addition, urbanization process around large city stations may have affected the rainy season precipitation to a certain extent in the Haihe River basin, with large and medium city stations experiencing around $10 \%$ higher precipitation than small city stations. However, this issue needs to be investigated exclusively.
\end{abstract}

Keywords: rainy season; precipitation; rainstorm; diurnal variation; urbanization; Haihe River; North China

\section{Introduction}

The Haihe River is the largest river in North China. Beijing, the capital of China, and Tianjin, a municipality directly under the central government, are both located in the river basin. Encompassing a total population of around 124 million, the Haihe River basin has the highest population density in the world but the lowest per capita water resources in China [1]. Intensive human intervention, excessive water resource exploitation and the severe impact of climate change in recent decades, have led to notable changes in the amount, quality and distribution of surface and underground water resources amidst the basin. The ever-increasing unbalance between supply and demand of water resources has become a key issue in the sustainable development of economy and society in the river basin. Accordingly, comprehensive knowledge on the spatial-temporal precipitation distribution 
and its causes has been of great importance for understanding the dynamic variation of runoff and groundwater, and for rationally planning and effectively managing the water resources in the basin.

The Haihe River basin has a semi-humid and semi-arid continental climate. As a river in the temperate East Asian Monsoon, more than $80 \%$ of its annual precipitation occurs from May to September. Affected by the terrain of North China, the high-rainfall belt stretches from northeast to southwest, roughly along the Yanshan and Taihang Mountains. There exist three rainstorm centers in the basin, located near Tangshan, the west of Baoding, and near Jinan, respectively [2,3]. The precipitation in summer is usually concentrated in several heavy rainfall occurrences, which endows the floods in the basin with the characteristics of a high peak value, a steep peak type and a large one-time volume [4]. The climatic factors dominating the summer rainfalls are extremely complicated [5]. On the one hand, the basin is located in the northern rim of summer monsoon activities, which enables the monsoon weather systems to influence the precipitation in the flood season [6,7]; On the other hand, it is also affected by the westerly circulation system at mid-high latitudes [2,8,9]. These factors lead to uneven spatial and temporal precipitation in the basin, aggravating the difficulty and uncertainty of water resources exploitation.

Plenty of researches have been conducted on the summer rainfalls in the Haihe River basin and North China. Ren et al. (2015) reported that the annual and summer precipitation in the Haihe River basin experienced a significant downward trend in the past 50 years. Since the mid-late 1970s, the annual precipitation in North China, including the Haihe River basin, has been further declining [10-12], with the abrupt decline in the rainy season rainfall after 1979 particularly significant [11]. Liu and Ding $[3,13]$ showed that there existed a decadal shift from high to low precipitation in North China around 1978. Hao et al. [14] found that the decreased precipitation in North China in the past 50 years was mainly due to the weakening of summer rainstorms.

With the establishment of the automatic weather station network and the accumulation of hourly precipitation data for years, attention has been paid to the fine resolution structures of precipitation [15,16]. Yu et al. [17] revealed that summer rainfalls in mainland China exhibit a remarkable spatial pattern of diurnal variations. In eastern China, for example, the peaks of precipitation mostly occur at around 17:00 and in early morning respectively. The diurnal variation of rainy season precipitation in central and eastern China shows a clear intra-seasonal evolution along with the north-south movement of the monsoon rain belt [18]. Zhou et al. [19] and Yuan et al. [20] analyzed the diurnal variation of summer rainfalls in the Huaihe River which is located between the Haihe River and the Yangtze River, concluding that there have existed two peaks, one before dawn and the other in the evening. Han et al. [21] adopted the satellite retrieved hourly precipitation data to analyze the diurnal variation of summer rainfalls in North China, and they found that the precipitation peaked late at night in the northern North China Plain, but in the morning in the central and southern parts of the plain.

Therefore, the long-term variations of precipitation and extreme rainfalls have been studied extensively in the past two decades, and the spatial-temporal precipitation distributions of summer rainfalls on different temporal scales have been examined as well. However, in-depth knowledge on diurnal precipitation variations, as well as on the more detailed spatial pattern and the relevant causes of seasonal and diurnal rainfall variations, has been far from enough considering that the adopted data in the previous works are relatively sparse in spatial distribution and coarse in temporal resolution.

In this paper, the high-density hourly precipitation observation data, which have been developed recently by the China Meteorological Administration, are used for the first time to analyze the refined spatial-temporal structure of precipitation with different durations in the Haihe River basin. The analysis reveals several novel features of precipitation in the basin, which is expected to lend support to a scientific understanding of the dynamic variations of atmospheric precipitation, surface and underground water resources in the region severely short of water. 


\section{Data and Methods}

The Haihe River basin is located between $112-120^{\circ} \mathrm{E}$ and $35-43^{\circ} \mathrm{N}$ (Figure 1), with a total area of 318,000 square kilometers. As one of the seven largest rivers in China, its basin covers Tianjin, Beijing, most parts of the Hebei province, as well as parts of the Henan province, Shandong province, Shanxi province and Inner Mongolia. The basin is bound to the north by the east-to-west Yanshan Mountains, and to the west by the north-to-south Taihang Mountains. Inside the basin, $60 \%$ of its surface is covered by mountains and plateaus, while the other $40 \%$ is covered by plains. The basin contains nine tributaries: the Luanhe River, the Beisan River, the Yongding River, the Daqing River, the Ziya River, the Zhangwei River, the Nanyun River, the Tuhai-majia River and the lower reach of the Haihe River.

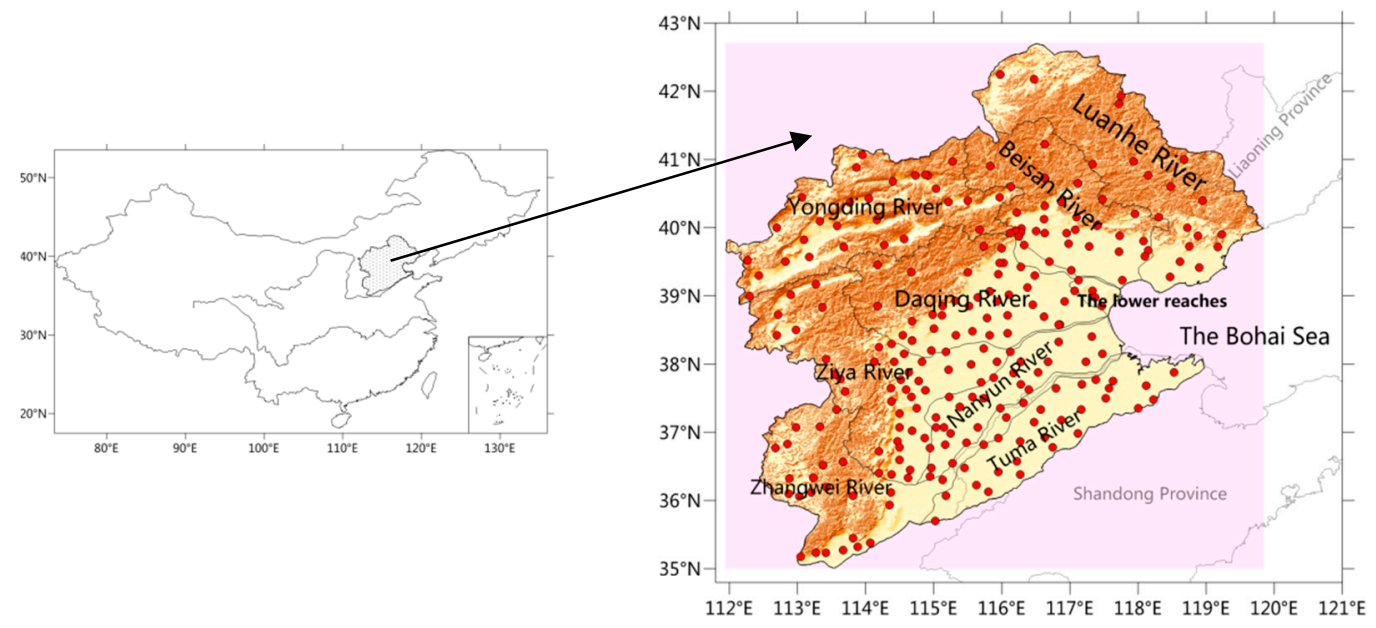

Figure 1. The geographical location and meteorological station distribution of the Haihe River basin (dots indicate locations of meteorological stations, and the purple color shows the mountains and plateaus).

The data used in this paper are the hourly precipitation observation data in the rainy season (May-September) during 2007-2017 from 249 meteorological stations in the Haihe River basin. The data are from the National Meteorological Information Center (NMIC), China Meteorological Administration (CMA). Quality control has been done for precipitation by the NMIC. A denser distribution of precipitation stations can be seen in the plain regions and the mountainous regions have relatively sparser observations (Figure 1).

In this research, a precipitation hour refers to an hour with precipitation greater than $0.1 \mathrm{~mm}$. Referring to previous studies [22,23], the length of the precipitation intermittence, as the boundary between two rainfall occurrences, is set to $2 \mathrm{~h}$. That is to say, when no rainfall occurs for two consecutive hours during a precipitation process, the process is judged to be terminated. In this case, discontinuous non-precipitation intervals might exist in a precipitation event. According to different durations, all of the precipitation events for any station are classified into four types in this work: short-duration precipitation (1-3 h), medium-duration precipitation (4-6 h), long-duration precipitation (6-12 h) and continuous precipitation (over $12 \mathrm{~h}$ ).

The analysis of diurnal variation uses Beijing local time at $120^{\circ} \mathrm{E}$. The intra-seasonal variation of rainfall during the rainy season is analyzed by applying the pentad mean rainfall for the period 2007-2017. Each month is thus divided into six pentads, with each of them being 5 days or six days (the last pentad of the months with 31 days) except for February that generally has three days or four days in the last pentad. A simple arithmetic average is made for the whole basin and its tributaries when calculating the areal means of precipitation amount and frequency on different time scales, by considering the relatively even distribution of the observational sites in the study region. In order to examine the possible influence of urbanization on precipitation, we classify the urban stations into 
three categories: large cities with a population over 5 million, medium-sized cities with a population 0.5-2 million and small cities with a population $0.1-0.5$ million. All other observational sites are regarded as rural stations.

\section{Results}

\subsection{Warm-Season Precipitation Distribution}

During 2007-2017, the rainy season precipitation averaged around $443.0 \mathrm{~mm}$ in the Haihe River basin. Among the tributaries, the Yongding River suffered the lowest precipitation of $337.3 \mathrm{~mm}$ while the Tuma River, in the south of the basin, had the highest precipitation of $486.8 \mathrm{~mm}$. The average precipitation in the Luanhe River, the Beisan River and the lower reach of the Haihe River stands at around $470 \mathrm{~mm}$. For other tributaries, the precipitation ranges between $400 \mathrm{~mm}$ and $450 \mathrm{~mm}$. In spatial distribution (Figure 2), there exist two high-rainfall zones and two low-rainfall zones, with the precipitation taking on the "high-low-high-low" pattern from southeast to northwest. The precipitation in the Tuma River downstream, in the south of the basin, stays above $520 \mathrm{~mm}$. The central plain receives low rainfalls of $460 \mathrm{~mm}$ or below, especially the Ziya River downstream where the precipitation is only $340-400 \mathrm{~mm}$. The windward (south) slope of the Yanshan Mountains sees high warm-season precipitation (460-560 $\mathrm{mm}$ on average); in this zone, the average precipitation in the Beisan River downstream and the Luanhe River downstream stays high at $520 \mathrm{~mm}$ or above. When it comes to the north of the basin, the precipitation of the plateaus stays below $400 \mathrm{~mm}$ on average, with the lowest value hitting $270 \mathrm{~mm}$. On the windward (east) slope of the Taihang Mountains, there also exists a zone with precipitation surpassing $460 \mathrm{~mm}$.

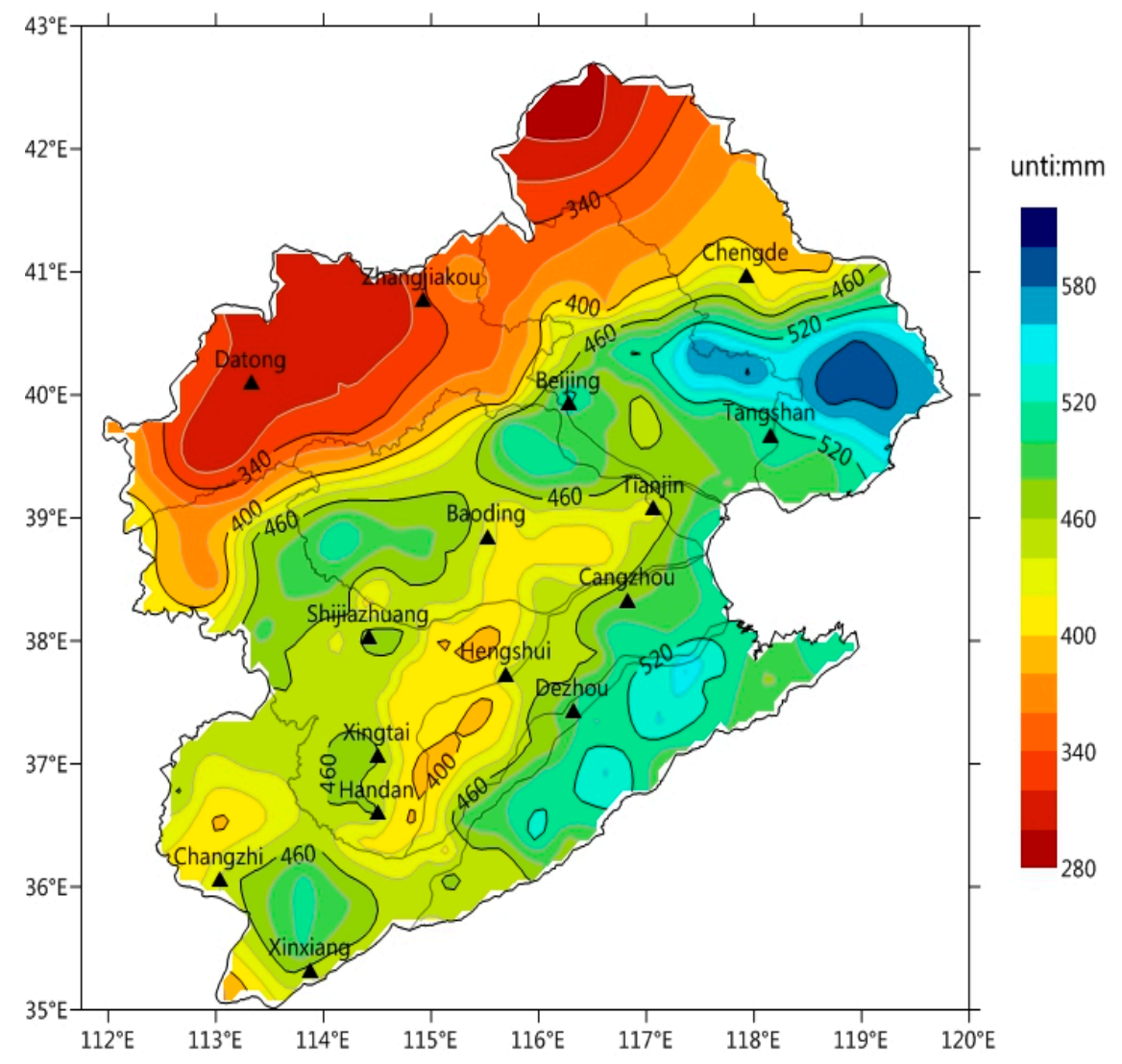

Figure 2. The spatial distribution of the rainy season total precipitation in the Haihe River basin, 2007-2014 (unit: mm). 


\subsection{Monthly Precipitation Pattern}

Figure 3 shows the spatial distribution of the monthly average precipitation during warm-season in the Haihe River basin. A visible difference can be found for the months.
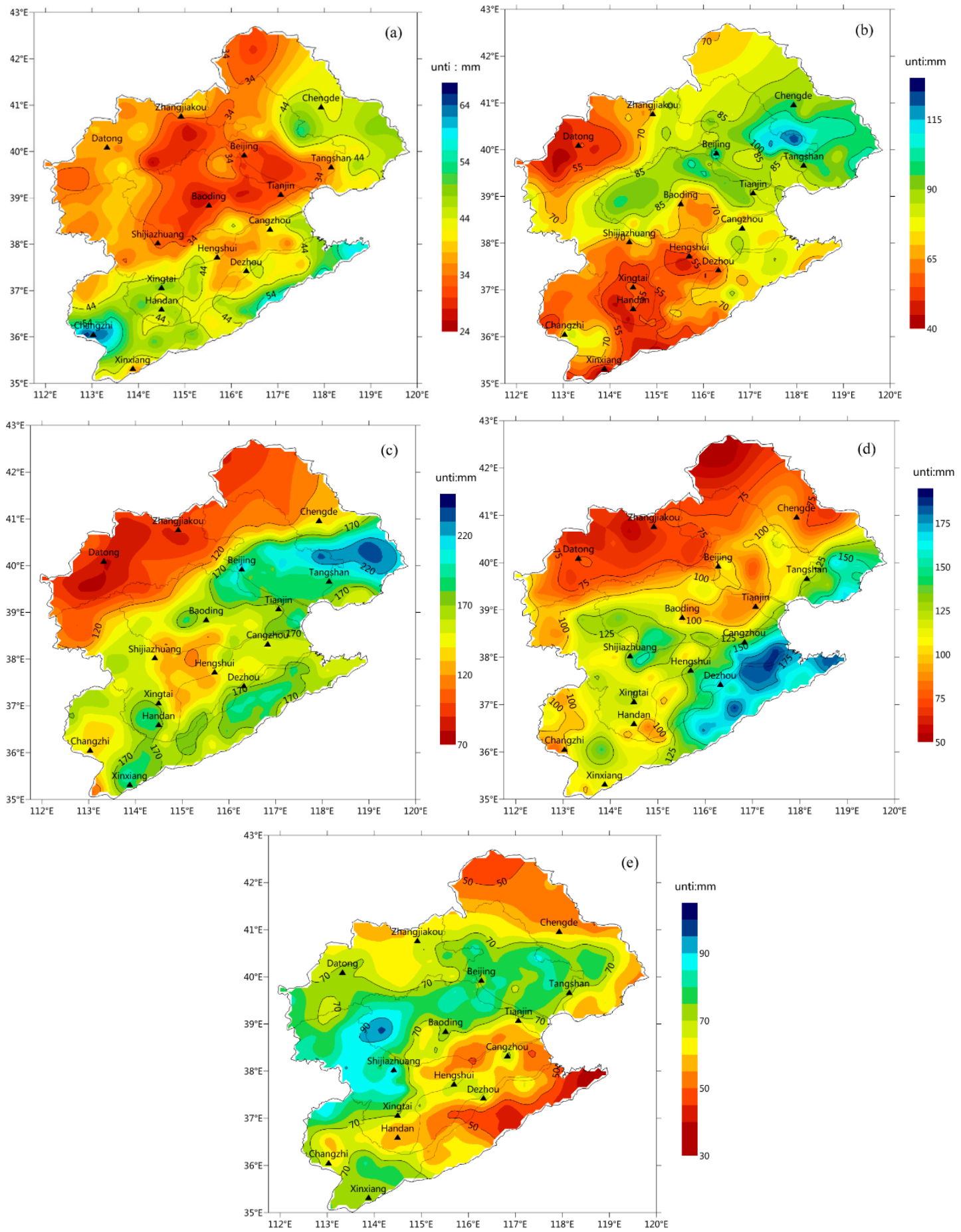

Figure 3. The spatial distribution of the monthly total precipitation in the Haihe River basin, 2007-2017 (unit: mm) ((a), (b), (c), (d) and (e) for May, June, July, August and September, respectively).

In May, the precipitation averages $36.8 \mathrm{~mm}$, accounting for $8.3 \%$ of the total precipitation in the rainy season. During this month, the Zhangwei River and the Tuma River in the south, as well as the Luanhe River in the northeast, are covered in the high-rainfall belt, suffering an average precipitation of over $40 \mathrm{~mm}$; while the Daqing River in the central basin is the zone with the lowest precipitation of 
$28.6 \mathrm{~mm}$. In June, the average precipitation climbed to $74.9 \mathrm{~mm}$, almost twice than that in May. In this month, rainfalls are high in the northeast while low in the southwest. The Luanhe River and the Beisan River in the north become the high-rainfall zones, with the average precipitation exceeding $90 \mathrm{~mm}$; while the Yongding River, the Ziya River and the Zhangwei River are the low-rainfall zones, with the average precipitation ranging between $59 \mathrm{~mm}$ and $65 \mathrm{~mm}$.

The precipitation is at $152.8 \mathrm{~mm}$ in July, over twice as much as in June. It accounts for $34.5 \%$ of the total precipitation in the rainy season. As for the spatial distribution, the precipitation in July indicates a "high-low-high-low" trend from south to north, similar to the pattern of the accumulative precipitation in the rainy season. The precipitation in the northern mountains and plateaus stays below $120 \mathrm{~mm}$. The central plain is also covered by a low-rainfall zone in this month. When it comes to August, the precipitation edges lower at $116.2 \mathrm{~mm}$, relatively high in the south while low in the north. The Tuma River, a high-rainfall zone in this month, has a level of precipitation of around $150 \mathrm{~mm}$. The precipitation in the plain is estimated at $100-150 \mathrm{~mm}$, and that in the mountainous area at $100 \mathrm{~mm}$ or below. As to September, the precipitation drops by around $80 \%$ from August. The spatial distribution is similar to that of June, except for the high-rainfall center which now moves to the northern Taihang Mountains. The Taihang Mountains and Yanshan Mountains become the high-rainfall zones while the southeastern part registers low rainfall, which is the opposite of August.

\subsection{Diurnal Precipitation Variations}

Figure 4 shows the diurnal variations of the average precipitation in the rainy season during 2007-2017 in the Haihe River basin. The diurnal variation curve has two peaks and a valley. The peak period takes place in the evening (17:00-21:00 h), with the hourly mean precipitation surpassing 21 $\mathrm{mm}$. The maximum value, occurring at 19:00 $\mathrm{h}$, is recorded at $21.9 \mathrm{~mm}$. The other peak occurs at 2:00 $\mathrm{h}$ when the hourly mean precipitation reads $20.2 \mathrm{~mm}$. The rainfall descends in the daytime (9:00-15:00 h), with the lowest precipitation occurring at noon (11:00-13:00 h). At 12:00 h, the hourly mean precipitation hits its low at $13.3 \mathrm{~mm}$.

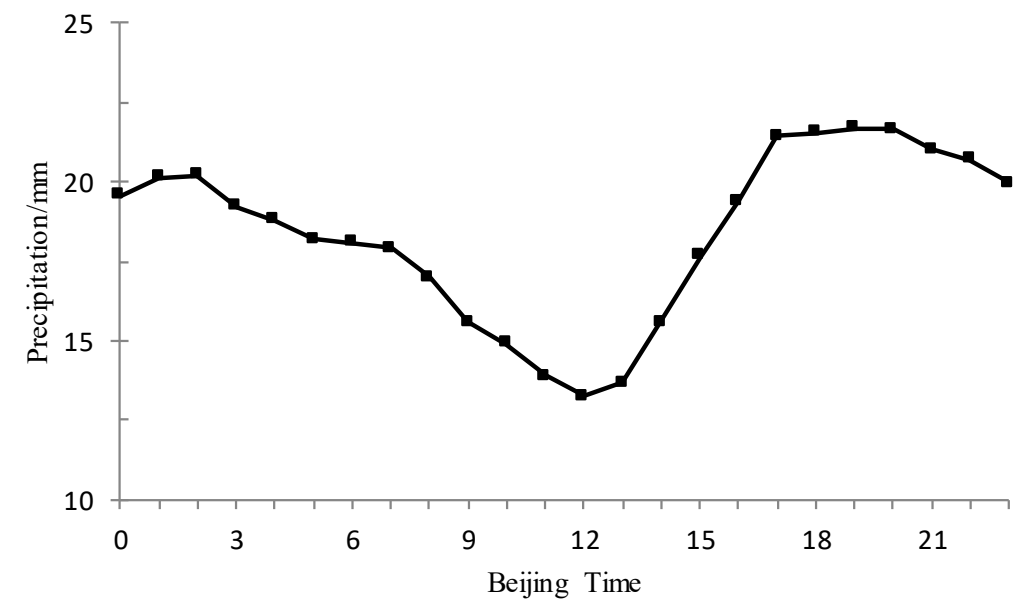

Figure 4. The diurnal variations of the basin-averaged hourly mean precipitation in the Haihe River basin.

Further analysis of the diurnal peak in each branch system shows that the occurrence periods vary greatly due to the difference in geographical location and topographic conditions (Figure 5). The precipitation in the Luanhe River, the Yongding River, the Beisan River, the Ziya River and the Zhangwei River increases during 15:00-17:00 h. The peak occurs during 21:00-23:00 $\mathrm{h}$ in the Beisan River, and other tributaries have the diurnal precipitation peak during 18:00-20:00 $\mathrm{h}$. 


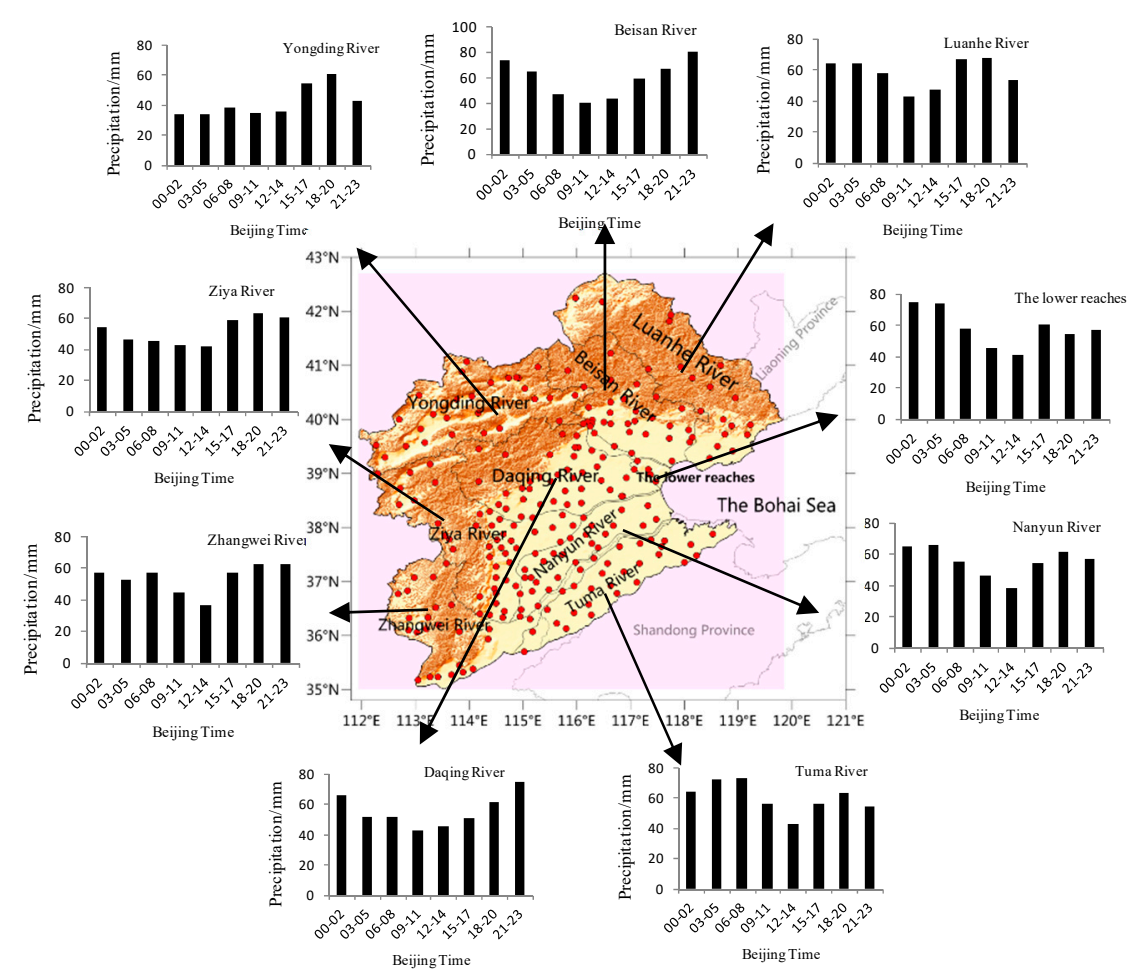

Figure 5. The diurnal variations of hourly mean precipitation for the tributaries in the Haihe River basin.

The diurnal precipitation in the lower reach of the Haihe River, the Nanyun River, and the Tuma River has two peaks, one at night and the other in the afternoon. The peak value at night is greater than that in the afternoon. Both the Nanyun River and the Tuma River reach an evening peak at 18:00-20:00 h; while the lower reach of the Haihe River encounters the afternoon peak at 15:00-17:00 h. As for night time, the peak in the lower reach of the Haihe River occurs at 0:00-2:00 h; while the peak in the Nanyun River and the Tuma River appears at 3:00-5:00 h.

\subsection{The Pentad Mean Precipitation Feature}

Figure 6 shows the pentad mean precipitation variations during 2007-2017 in the Haihe River basin. The pentad mean precipitation during the summer could be divided into five periods. From May to the fourth pentad of June, the hourly mean precipitation stays low at $0.1-5 \mathrm{~mm}$. The diurnal precipitation, high at night but low in the daytime, mostly occurs at 16:00-20:00 $\mathrm{h}$ but seldom appears between 5:00-15:00 $\mathrm{h}$ (especially at noon) during this period. During the fifth pentad of June and the third pentad of July, the hourly mean precipitation climbs from the previous period to as high as 5-10 $\mathrm{mm}$. During this period, the diurnal peak appears at 18:00-21:00 $\mathrm{h}$. The major flood season of the Haihe River arrives at the period from the fourth pentad of July to the second pentad of August, or from late July to early August. In this period, the hourly mean precipitation stays high at $10-20 \mathrm{~mm}$. The diurnal peak and sub-peak reach at 17:00-22:00 $\mathrm{h}$ and 0:00-7:00 $\mathrm{h}$ respectively, with the hourly mean precipitation averaging around $15 \mathrm{~mm}$. Later from the third pentad of August to the second pentad of September comes the post-flood season of the study region. In this period, the hourly mean precipitation slides to $5-10 \mathrm{~mm}$. The precipitation mainly occurs at night and peaks at 0:00-8:00 $\mathrm{h}$. During the third pentad and the sixth pentad of September, the hourly mean precipitation further drops to $0-5 \mathrm{~mm}$. The night time in this period sees most of the rainfalls. It could be concluded that fewer rainfalls come in the daytime (9:00-15:00 h) for all the five periods, although the peaks vary. 


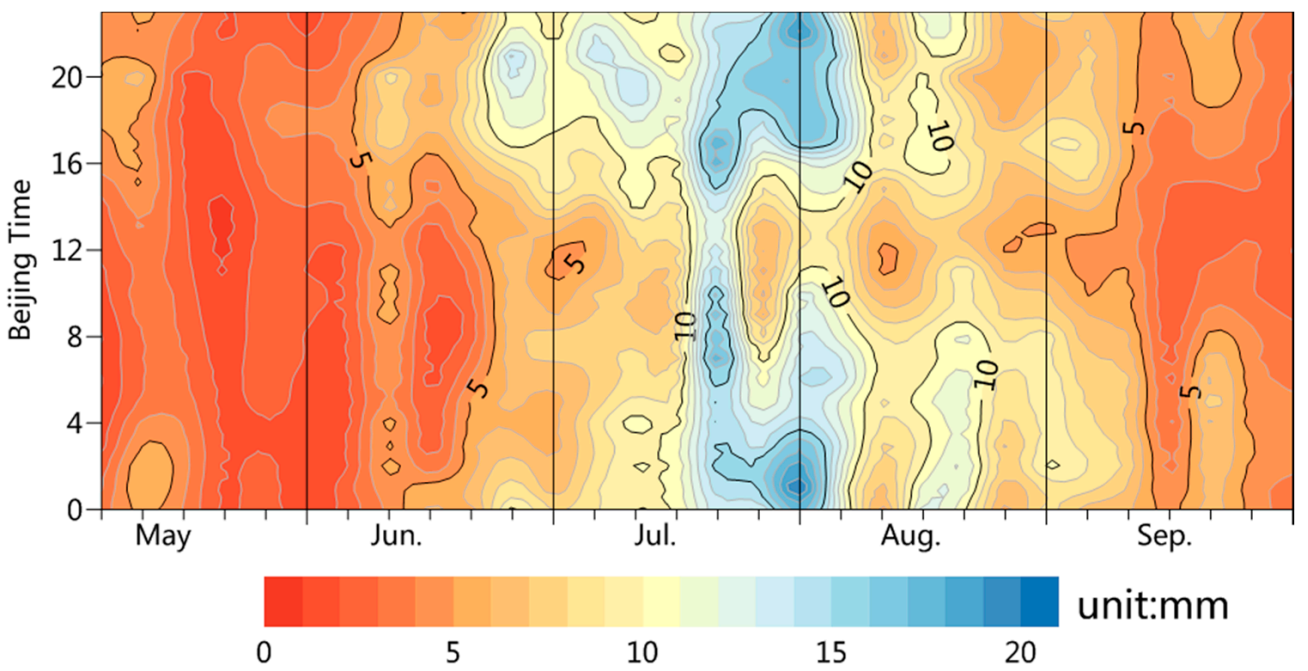

Figure 6. The pentad variations of the hourly mean precipitation in the Haihe River basin, 2007-2017.

The seasonal precipitation of each tributary is featured with a single peak in the diurnal variation. July has the highest precipitation of the rainy season, followed by August, and May witnesses the lowest precipitation. The tributaries share a similar diurnal variation pattern (Figure 7). During the first pentad of May and second pentad of July, the diurnal precipitation of each branch reaches a single peak, with most rainfall coming in the afternoon or at night. From the third pentad of July till the fourth pentad of August (major flood season), the peak of the hourly mean precipitation occurs before dawn in the Luanhe River, the Beisan River, the Nanyun River, the Zhangwei River, the Tuma River and the lower reach of the Haihe River. As for the Beisan River, the Yongding River, the Daqing River and the Ziya River in the mountainous areas, the peak appears in the afternoon or at night. The lower reach of the Haihe River, the Nanyun River and the Tuma River also witness high rainfalls for one hour in the afternoon.
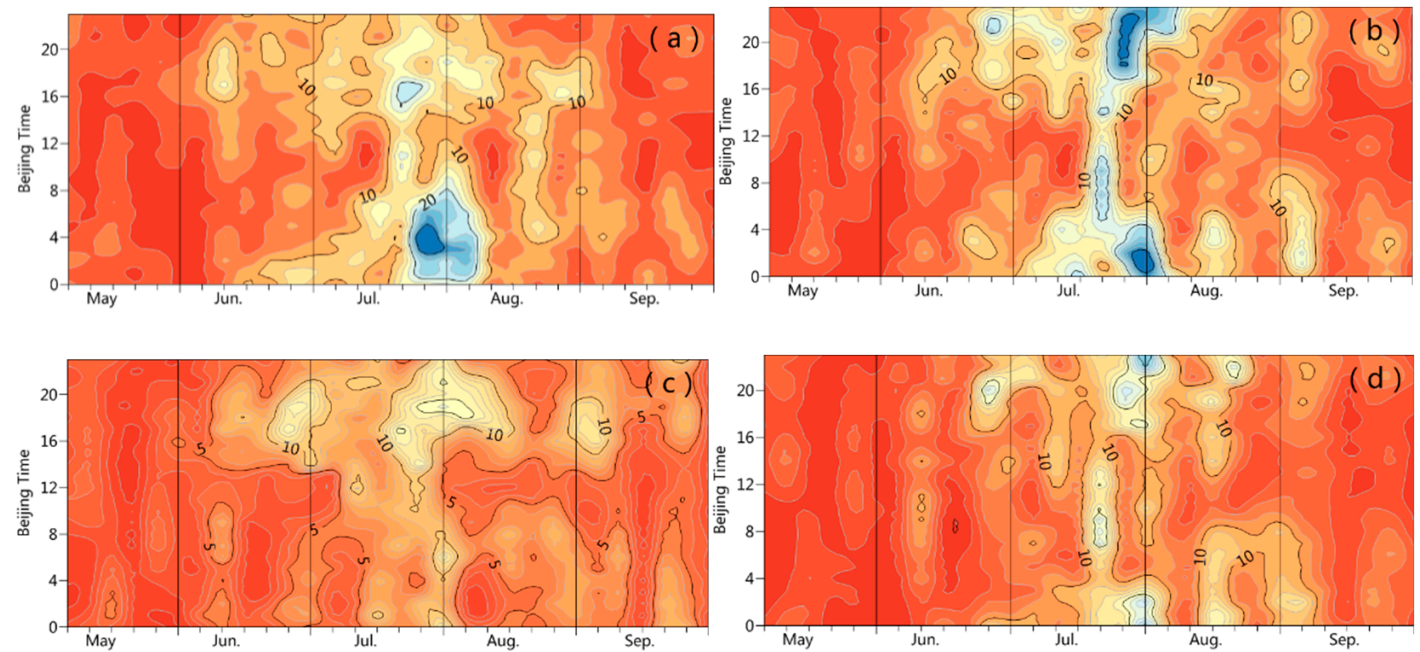

Figure 7. Cont. 

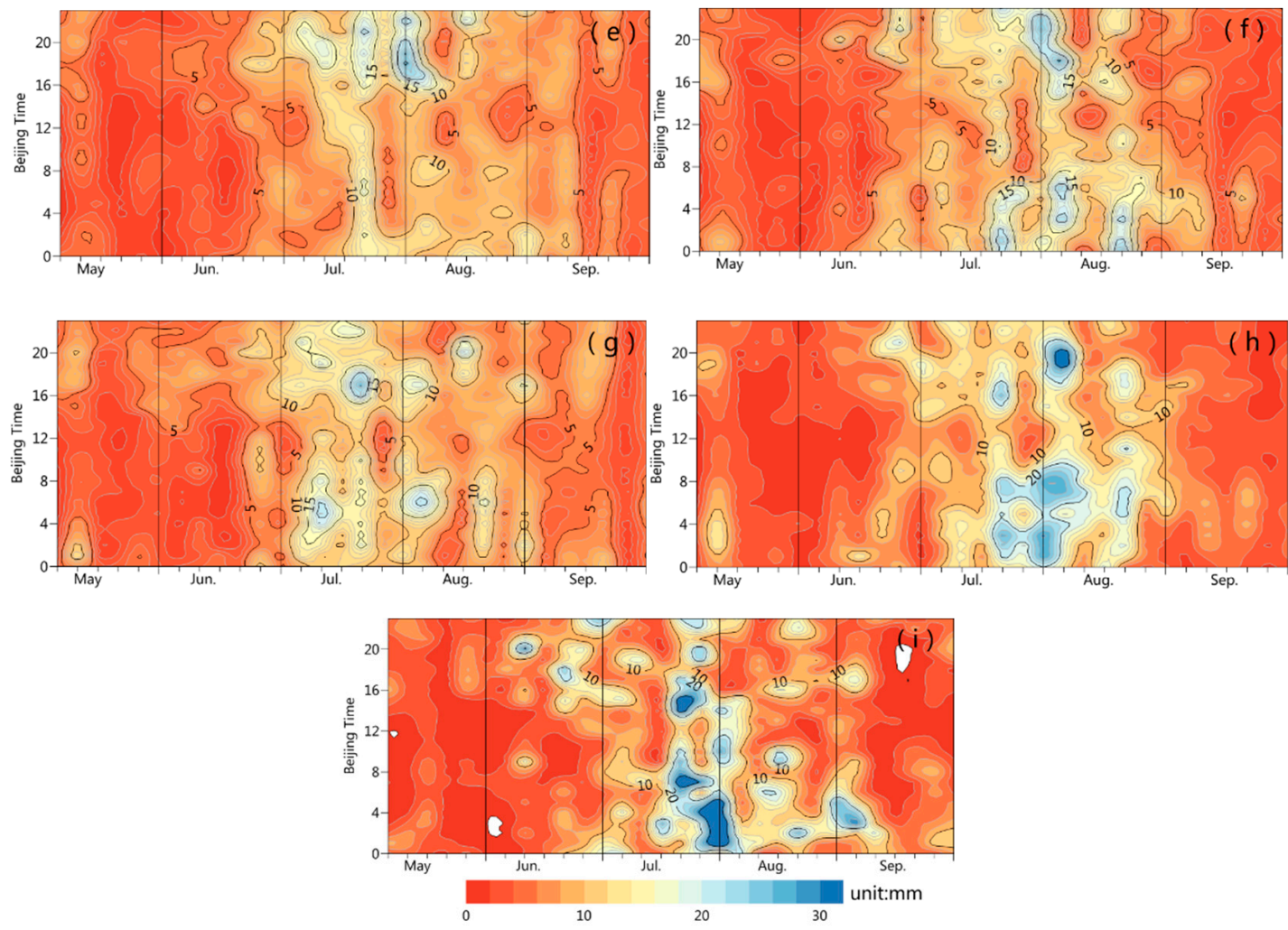

Figure 7. The pentad variations of the hourly mean precipitation for tributaries in the Haihe River basin, 2007-2017. ((a), Luanhe River; (b), Beisan River; (c), Yongding River; (d), Daqing River; (e), Ziya River; (f), Nanyun River; (g), Zhangwei River; (h), Tuma River; (i), low reach of Haihe River).

\subsection{Duration-Based Precipitation Features}

The precipitation events are classified into four types of short-duration (1-3 h), medium-duration (4-6 h), long-duration (6-12 h) and continuous precipitation (over $12 \mathrm{~h}$ ). Figure 8 shows that the diurnal peaks of the short-duration and medium-duration precipitation appear at around 18:00 $\mathrm{h}$ and 22:00 $\mathrm{h}$, respectively, and the peaks of the long-term duration and continuous precipitation appear before dawn.
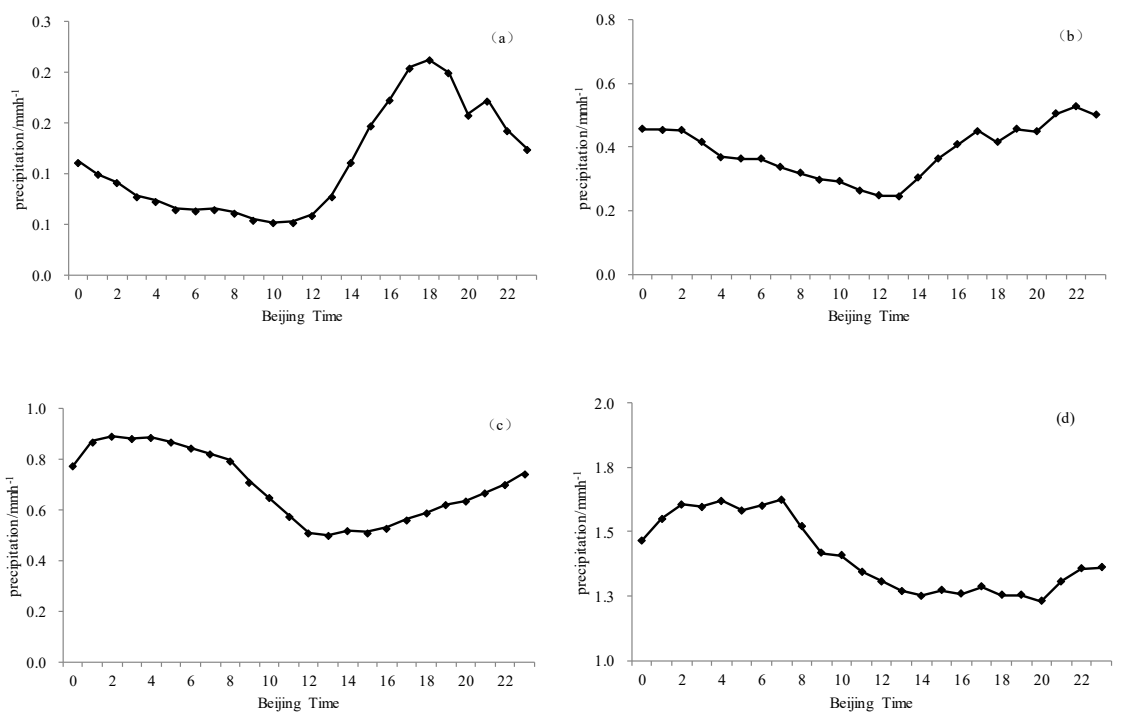

Figure 8. The diurnal variations of the different duration precipitations in the Haihe River basin, 2007-2017 ((a), short-duration (1-3 h) precipitation; (b), medium-duration (4-6 h) precipitation; (c), long-duration (6-12 h) precipitation; and (d), continuous precipitation (over $12 \mathrm{~h}$ ) precipitation). 
Figures 9-11 show the spatial distribution of the warm-season mean precipitation frequency, amount and contribution for different duration precipitation events in the Haihe River basin during 2007-2017.
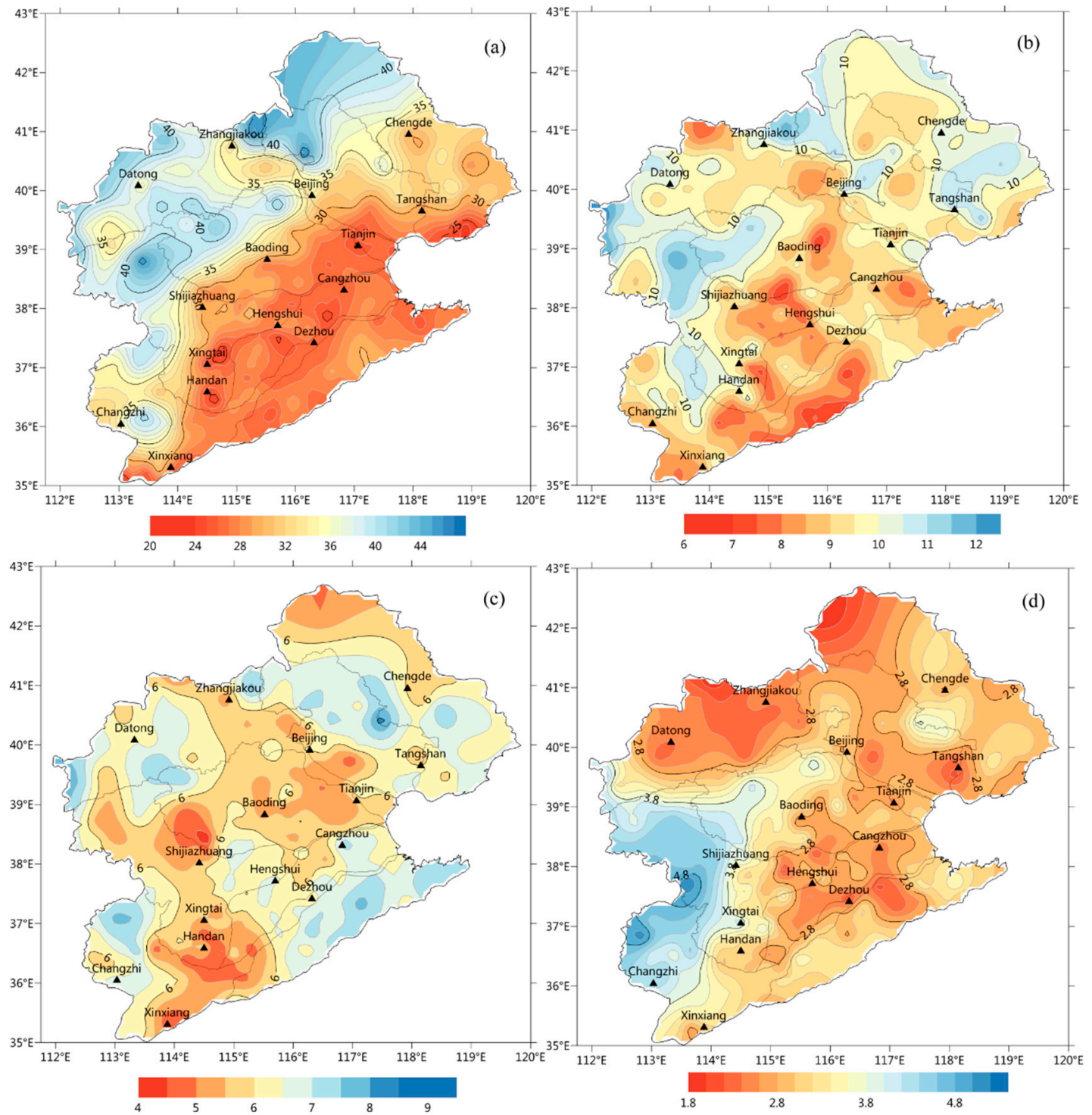

Figure 9. The precipitation frequency with different durations in the Haihe River basin, 2007-2017 (unit: hour) ((a), short-duration (1-3 h) precipitation; (b), medium-duration (4-6 h) precipitation; (c), long-duration (6-12 h) precipitation; and (d), continuous precipitation (over $12 \mathrm{~h}$ ) precipitation).

In the whole basin, the short-duration precipitation has the highest frequency, with an average of 20 to 45 occurrences per year. The short-duration precipitation in the northwest has more occurrences than that in the plain areas. The annual occurrence of short-duration precipitation in the plain areas is below 30 times, while that in the mountainous areas generally exceeds 30 times on average. In the upper reaches of the Luanhe River and the Beisan River, most parts of the Ziya River, as well as borders between the Daqing River and the Yongding River, the warm-season mean occurrence of short-duration precipitation reaches above 40 times (Figure 9a). The probability of short-duration rainfalls in these areas is relatively large from afternoon to early evening (Figure 5). The accumulative amount of short-duration precipitation in the mountainous areas lingers even at the range of 60 to 90 $\mathrm{mm}$ (Figure 10a), contributing to around 30\% of the total rainfalls in the rainy season (Figure 11a). 

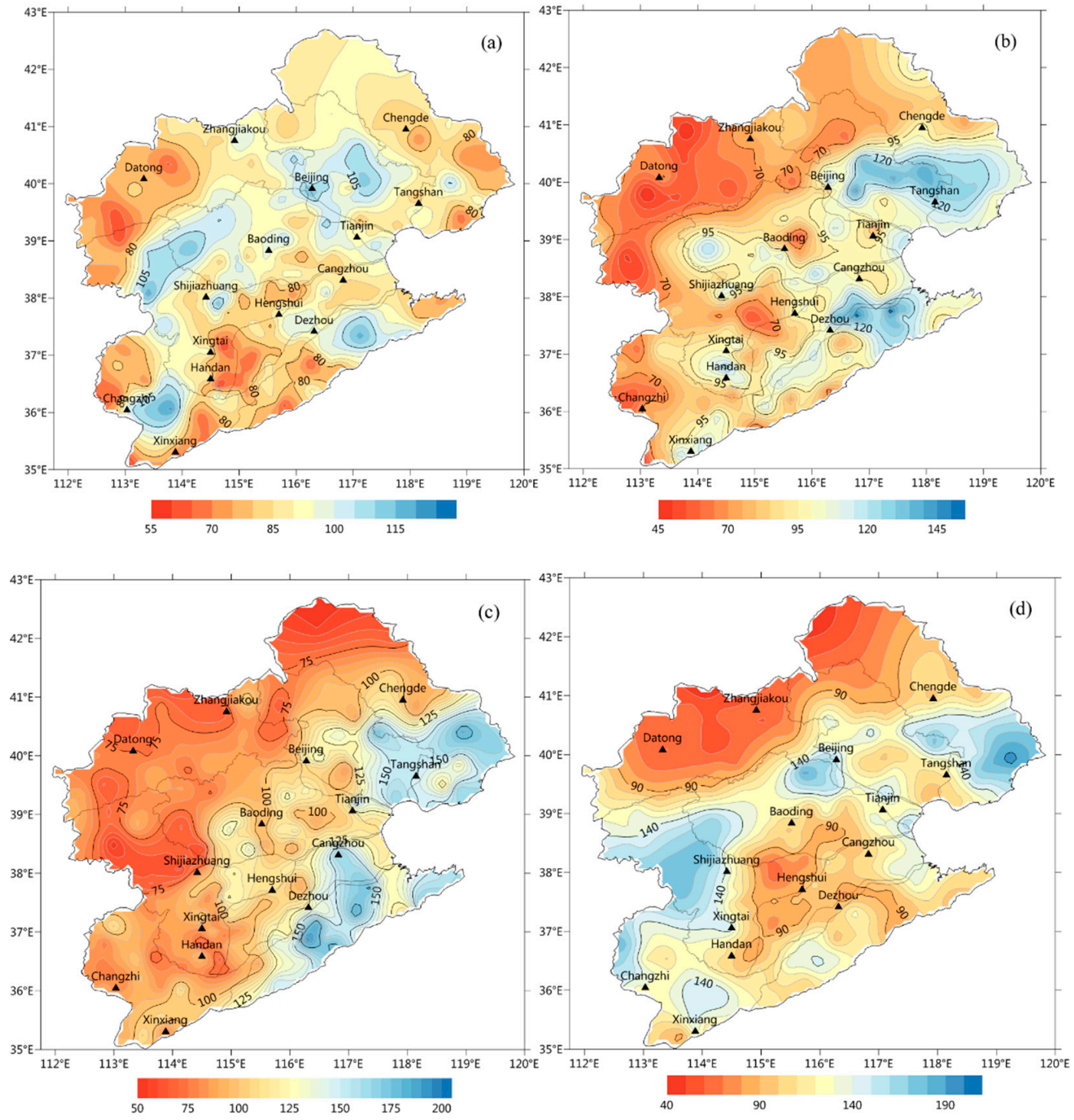

Figure 10. The precipitation amount with different durations in the Haihe River basin, 2007-2017 (unit: $\mathrm{mm})((\mathbf{a})$, short-duration (1-3 h) precipitation; (b), medium-duration (4-6 h) precipitation; (c), long-duration (6-12 h) precipitation; and (d), continuous precipitation (over $12 \mathrm{~h}$ ) precipitation).

The occurrence of medium-duration precipitation during the rainy season is 6 to 12 times on average. Specifically, it happens for more than 10 times in the east of the Taihang Mountains and the lower reach of the Luanhe River, and for 8 to 10 times in other areas (Figure 9b). The medium-duration precipitation is high in the east but low in the west. The mean precipitation amount in the lower reach of the Luanhe River surpasses $120 \mathrm{~mm}$, contributing around $25 \%$ to rainy season rainfalls. This corresponds to the high-value area of the precipitation frequency. Though the precipitation frequency stays high in the east of the Taihang Mountains, the accumulative precipitation amount remains low with a contribution rate below $20 \%$ (Figures $10 \mathrm{~b}$ and $11 \mathrm{~b}$ ).

The long-duration precipitation and continuous precipitation in the Haihe River basin occur less frequently, with annual mean frequencies of 6.1 times and 3.1 times, respectively. However, the spatial distribution of the two categories is quite different. The highly-frequent occurrences of long-duration precipitation are found in the windward slope of the Yanshan Mountains, the Tuma River and parts of the Nanyun River (Figure 9c); while continuous precipitation mainly occurs in the Taihang Mountains and its eastern slope, as well as the lower reach of the Luanhe River (Figure 9d). The high-value areas of the warm-season mean precipitation amount are basically compliant with the precipitation frequency. 
Specifically, the high-value areas of long-duration precipitation cover the eastern part of the basin (Figure 10c), with a contribution at around 30\% (Figure 11c); those of continuous precipitation include the Taihang Mountains and the west of the Yanshan Mountains' windward slope, with a contribution rate staying above $30 \%$.
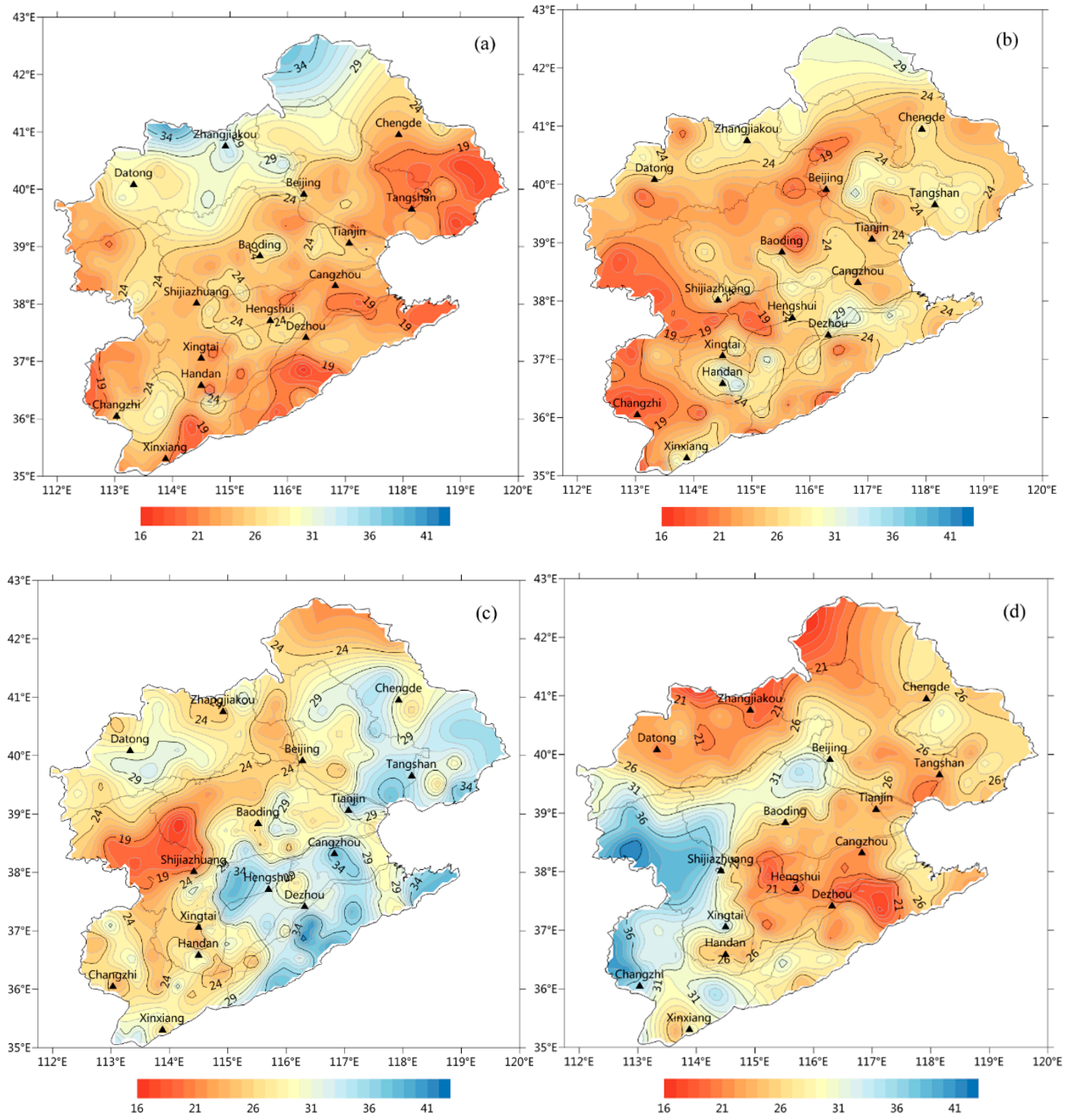

Figure 11. The precipitation contribution (to the total rainfall) with different durations in the Haihe River basin, 2007-2017 (Unit: \%) ((a), short-duration (1-3 h) precipitation; (b), medium-duration (4-6 h) precipitation; (c), long-duration (6-12 h) precipitation; and (d), continuous precipitation (over $12 \mathrm{~h}$ ) precipitation).

Above all, the short-duration precipitation contributes significantly to the total rainfalls in the northern mountainous areas (Figure 11a); while in the plain areas, the long-duration precipitation contributes more (Figure 11c). The high-value areas of continuous precipitation lie in the Taihang Mountains and its east slope. On average, the long-duration and continuous precipitation amounts contribute more to rainy season rainfalls than the short-duration precipitation, indicating that the continuous precipitation caused by the large-scale circulation of the East Asian summer monsoon has a greater impact on the precipitation in the Haihe River basin. 


\section{Possible Impacts from Urbanization}

The basin has 10 large cities of over 5.0 million residents, 27 medium-sized cities of 0.5-2.0 million residents, as well as 21 small cities of over $0.1-0.5$ million residents. All other stations are regarded as non-city stations. Due to the much larger number of the non-city stations, and also the obviously different altitudes and environments from those of the city stations, only the differences of precipitation among the different categories of cities are compared here.

Figure 12 shows that the mean precipitation in the rainy season is the lowest in the small cities, and that in the large cities is slightly higher compared with the medium-sized cities. From the perspective of the pentad mean precipitation, the three categories of cities share little difference in precipitation in May, June and September when the precipitation is low. During July and August, however, the pentad mean precipitation of large cities is larger than those of medium-sized cities and small cities, indicating that larger rainfalls are more likely to occur in large cities during the rainiest months of a year.
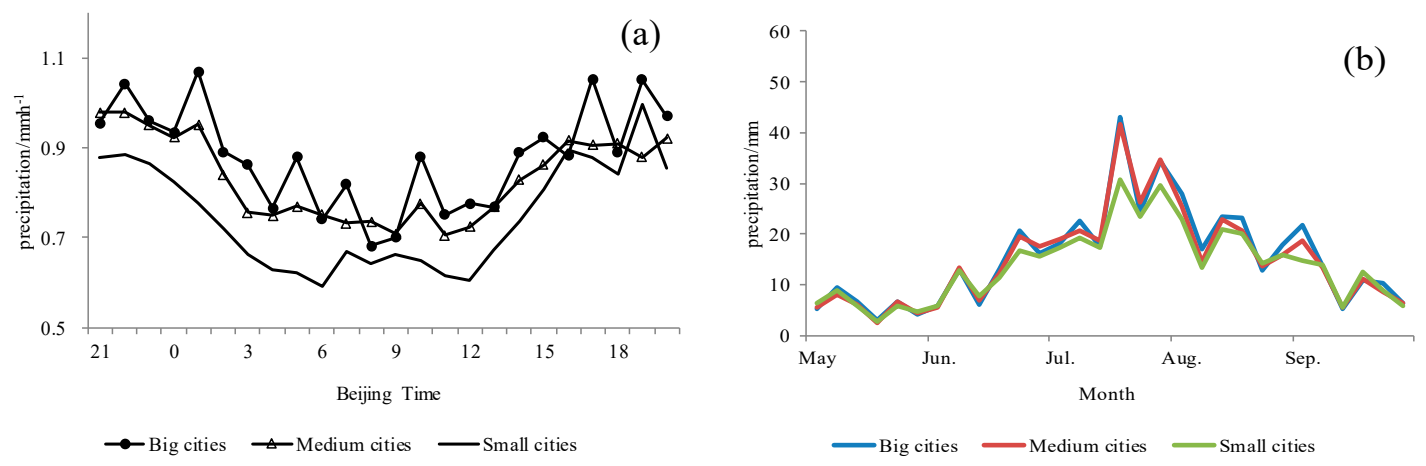

Figure 12. The diurnal precipitation variations (hourly mean precipitation) (a) and intra-seasonal variations (pentad mean precipitation); (b) for different categories of cities, 2007-2017.

Overall, the annual total precipitation during the 11 years is $49.8 \mathrm{~mm}$ or $12 \%$ higher at the large city stations than that at the small city stations, and $33.8 \mathrm{~mm}$ or $8 \%$ higher at the medium-sized city stations than that at the small city stations (Table 1). The city stations are located at approximately similar elevations, with the large city station slightly lower than the medium-sized city stations, and $300 \mathrm{~m}$ lower than the small city stations (Table 1). Therefore, the possible effect of altitude on the precipitation difference between large city and medium-sized city stations can be ruled out due to having almost the same altitudes, but the precipitation differences of small city stations from those of large city and medium-sized city stations would be, to some extent, affected by the altitude difference. Figure 13 shows the relationship between warm-season precipitation of all the non-city stations and their altitudes. A weak but significant negative correlation is notable and unexpected, and the decreasing rate of precipitation with altitude in the whole river basin is $-7.9 \mathrm{~mm} / 100 \mathrm{~m}$. This relationship between precipitation and altitude could be regarded as the background lapse of rainfall in the basin. Considering this influence of altitude, however, the warm-season precipitation at large city stations $(459.9-24.4=435.5 \mathrm{~mm})$ is still obviously higher $(6.2 \%)$ than that at the small city stations at the same altitude, and the precipitation at the medium-sized stations is marginally higher $(2.5 \%)$ than that of the small city stations. 
Table 1. The average altitudes and warm-season mean precipitation of the city stations in the Haihe River basin, 2007-2017.

\begin{tabular}{ccccc}
\hline $\begin{array}{c}\text { Categories of } \\
\text { Stations }\end{array}$ & $\begin{array}{c}\text { Number of } \\
\text { Stations }\end{array}$ & $\begin{array}{c}\text { Average Altitude } \\
\text { (m asl) }\end{array}$ & $\begin{array}{c}\text { Mean Precipitation } \\
\text { (mm) }\end{array}$ & $\begin{array}{c}\text { Difference from } \\
\text { Small City (mm) }\end{array}$ \\
\hline Large city & 10 & 34.8 & 459.9 & $49.8(12 \%)$ \\
Medium-sized city & 27 & 43.4 & 443.9 & $33.8(8 \%)$ \\
Small city & 19 & 343.8 & 410.1 & \\
\hline
\end{tabular}

Note: asl-above sea level; Percentage is the proportion of the difference to precipitation of small city.

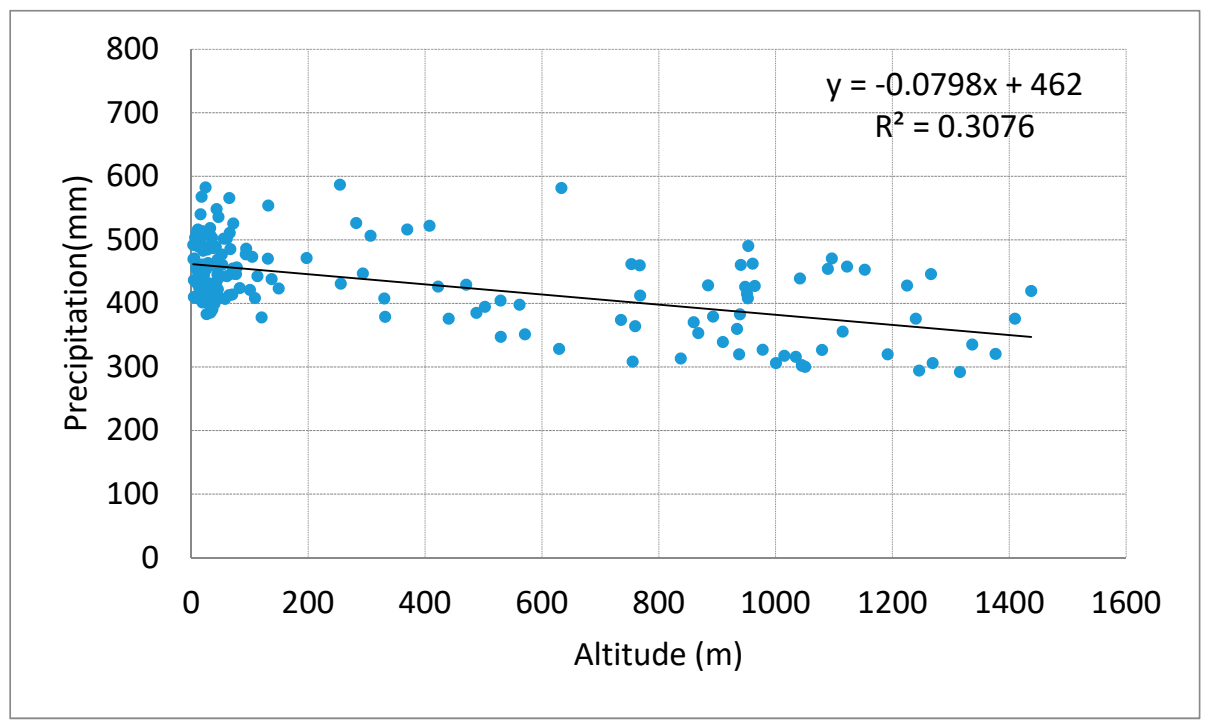

Figure 13. The relationship between warm-season precipitation of non-city stations and their altitudes in the Haihe River basin, 2007-2017.

Therefore, the warm-season precipitation at the large and medium city stations shows a notable difference from that of the small city stations, and this may have been related to the influence of urbanization on the thermal and dynamical processes of lower troposphere over the urban areas during the rainiest months of summertime.

\section{Discussion}

This paper has made a detailed examination of rainfall in the rainy season over the Haihe Basin, based on a high-density precipitation observational network as developed in the last decade. The work reveals a couple of interesting phenomena, and they are partially consistent with the previous analyses, but some of the phenomena are unique and worth a discussion and further investigation.

\subsection{Spatial and Intra-Seasonal Variations}

It could be seen that the distribution of rainy season rainfalls (Figure 2) is mainly affected by topography and prevailing winds in the Haihe River basin. In cases where easterly winds and southerly winds prevail, rainfalls are much likelier to occur on the windward slopes of the mountains due to forced uplifts by topography $[24,25]$. The highest-rainfall zone in the basin is found on the windward slope of the Yanshan Mountains, with the rainy season precipitation exceeding $520 \mathrm{~mm}$ on average. Within this zone, the average warm-season precipitation in Qinglong station has even reached $591 \mathrm{~mm}$.

Regarding the summer rainfall and its intra-seasonal variation in the river basin (Figures 2 and 3), previous studies showed that they are mainly affected by the East Asian summer monsoon. The location change of the West Pacific Subtropical High (WPSH) ridge in summer directly affects the distribution of water vapor transport flux in this basin. There are three water vapor transport channels influencing the 
summer rainfalls. The first one flows from the Indian Ocean and the Bay of Bengal, passing through the Indo-China Peninsula, reaching the South China Sea, turning into the southwest air stream and then reaching the Haihe River Basin; as for the second flow, the air stream in southwest of the WPSH carries water vapor from the West Pacific and the South China Sea through the southeast coast to the Haihe Basin River; the third flow originates from the mid-latitude westerlies, which transports water vapor from the west to east $[14,26,27]$.

Before the end of June, the WPSH ridge is located at the south of $25^{\circ} \mathrm{N}$, with the East Asian summer monsoon not yet extending the North China region. The Haihe River basin is jointly affected by the northwest air current as well as the southern warm and humid air current. The water vapor mainly comes from the southwest air current. In late July and early August, as the WPSH moves northwards, the air current in the southwest of the WPSH affects the basin. Overhead from the South China Sea to the West Pacific, the water vapor is transported abnormally to the west and northwest. The air current and the enhanced summer monsoon in Southeast China constitute an anticyclonic abnormal water vapor transport belt, which brings the water vapor northwards to the Haihe River basin. After mid-August, along with the weakening of the WPSH, the high ridge-line begins to retreat rapidly from north to south. With the southeast wind sweeping North China, the basin receives water vapor from the Philippine Sea and the East China Sea [28,29].

The combined influence of the WPSH and water vapor transport, and the special topography could well explain the different patterns of monthly precipitation distribution in the Haihe River basin. For example, the high precipitation in the Beisan River and the Luanhe River in June and July-mainly formed by the interaction between the prevailing southwestern-lies at the low troposphere and the windward slopes of the eastern Yanshan mountains, and the relatively high precipitation on the eastern slope of the Taihang Mountains in September is caused by the prevailing near-surface southeast currents which bring the water vapor from the East China Sea and the Yellow Sea. The small sub-centers of precipitation in the plains may be related to the urbanization effect, which will be discussed below.

\subsection{Diurnal Variation of Rainy Rainfall}

As is shown in Figure 5, the whole basin and all the tributaries generally see high precipitation at night and before dawn, and low precipitation in the daytime, with the lowest precipitation reached during 9:00-14:00 h. This complies with the conclusion by Yu et al. [17] that high precipitation in northern China mainly occurs at midnight and before dawn.

Precipitation in the sub-basins witness different diurnal variations, but mostly more rainfall occurs in the late afternoon and evening, as shown in Figure 5. There is a small distinction (less than half an hour) between the local time and Beijing time, and the time difference would not significantly affect the analysis results of the diurnal variation between the eastern and western sub-basins. The sub-basins with rainfall mostly in the late afternoon and evening are mainly located in mountainous areas with higher altitudes. Convection enhancement and unstable stratification caused by solar radiation in the afternoon, as well as the uplifting effect of valley wind circulation, increases the probability of rainfalls during the afternoon to evening.

On the other hand, precipitation in the plains and coastal areas mostly occurs before dawn (Figure 5), which is mainly attributed to the declination of the valley wind circulation at night and the effects of the sea-land breeze daily variation caused by differences in the sea-land thermal difference. In the latter case, from midnight to early morning, as the atmosphere over the ocean is warmer than that over the continent, the air rises in the ocean and coastal areas, causing uplifts and precipitation. Radiative cooling at the top of the cloud at night causes the boundary layer to become unstable and also promotes convection over the ocean and coastal areas. Therefore, precipitation on the sea usually occurs in the late-night hours. Due to the influence of offshore areas, the diurnal precipitation variation at coastal areas is also featured with a peak before dawn. Yin et al. [23] indicated that the spatial differences of the diurnal variation of summer rainfall in the Haihe River basin are mainly impacted by the valley circulation and the land-sea breeze circulation. In the afternoon, upward movement 
occurs in the mountains in the western and northern Haihe River basin, which goes in line with the precipitation peak in this period. Meanwhile, downward movement occurs in the coastal and plain areas, resulting in the low frequency of precipitation in the afternoon.

Pentad variations of hourly mean precipitation for tributaries in the basin (Figure 7) basically go in accordance with previous studies [30]. Previous studies have also shown that thermal circulation of the valley wind is an important cause of the difference between mountainous areas and plains in terms of the diurnal precipitation variations in the Haihe River basin during the rainy season [31]. Along the Yanshan-Taihang Mountains, the precipitation peak occurs mostly in the afternoon because of the solar radiative heating and the uplifting of the air in the mountainous areas. Then the upper air moves downstream and to the southeast dragged also by the middle troposphere average air current, resulting in a substance of air and a suppression of precipitation during the afternoon. This may benefit the precipitation peak in the afternoon in the mountains and at night in the plain area [31]. After mid-August, the monsoon rain belt retreats and precipitation gradually decreases.

The short-duration and medium-duration precipitation peak at around 18:00 $\mathrm{h}$ and 22:00 $\mathrm{h}$, respectively, and the long-term duration and continuous precipitation reach the highest level before dawn (Figure 8). These characteristics are approximately consistent with the results of previous studies $[20,32]$ which reported that the short-duration precipitation had a diurnal peak in the evening while the long-duration and continuous precipitation peaks before dawn.

\subsection{Impact of Urbanization}

From the analysis on the mean precipitation with different durations and their contributions to warm-season precipitation, it could be found that high-value centers exist near large cities including Beijing, Tianjin, Shijiazhuang, Baoding, Xingtai and Handan. Previous research on the precipitation features in Beijing [33-35] showed that urban areas suffer more rainfalls and more frequent intense rainfall events than rural areas. This paper shows the generally larger rainfall at large and medium cities than at the small cities, indicating a highly possible influence of urbanization on rainfall in the summer. This is a very interesting issue and certainly deserves further investigation in the future.

The precipitation differences of large and medium-sized city stations from that of small city stations, as shown in Figure 12 and Table 1, may have been caused mainly by the development of the built-up areas or urbanization process in the larger cities. The mechanisms of the urbanization effect are clearly understood. Three aspects are important: the urban heat island (UHI) effect which causes stronger air uplifting within the urban areas by developing a UHI circulation, the enhanced surface roughness due to the high buildings, which acts as a driver to strengthen convergence of currents and to block the weather systems, and the denser air pollutants in urban areas, which may act as effective nuclei for water droplets and ice to form in clouds in the rainy season [36].

A complicated situation may arise when discussing the impact of urbanization on precipitation. Zheng and Ren [37] found that wind speed affects the precipitation capture rate of the gauge, leading to precipitation observation errors, especially for heavy rainfalls and above-grade rainfalls, in the Beijing City and the surrounding areas. Under the influence of wind speed, the precipitation might be underestimated by 7-9\%. Urbanization causes not only the urban warming or the UHI effect, but also the weakening of near-surface wind speed within the urban areas, leading to an increase in the capture rate of the gauge [38]. It is possible, therefore, that the relatively higher precipitation and intense rainfall in the urban areas are induced partly by the larger capture rate of the gauge due to the weaker wind. If the under-catch effect exists, then the wind-induced bias in observations has to be adjusted before any further analysis can be made to examine the impact of urbanization on the mean and intense precipitation at urban stations of the Haihe River basin.

Therefore, the issue of urbanization effect on summer precipitation has to be better settled after the error of the gauge measurement is adjusted, and also a more sophisticated methodology is developed in the future. 


\section{Conclusions}

This study analyzes the intra-seasonal and diurnal precipitation variations in the Haihe River basin and its branch systems, based on the hourly precipitation data in the rainy season (May-September) during 2007-2017. The following conclusions can be drawn from the analysis:

(1) The high-rainfall belt in the basin moves with the summer monsoon from south to north and then back to the south. The belt is located in the south of the Yanshan Mountains and the Tuma River. Multiple rainstorm centers are found amidst the rainy belt. Throughout the rainy season, the high-rainfall zones could be found more in the windward slope of the Yanshan Mountains and in the south of the basin.

(2) The precipitation of each branch system is featured with a single peak during the rainy season. Specifically, the precipitation keeps low before early July and strikes the bottom in May, which is marked as the pre-flood season. It peaks in July, with the major flood season coming from the third pentad of July to the fourth pentad of August. The precipitation in August ranks second, only after that in July. However, it begins to decrease after mid-August, which is named as the post-flood season.

(3) The precipitation is high at night but low during the daytime generally within the basin; still, the high-rainfall period differs among tributaries. Along with the movement of the high-rainfall belt, the precipitation in the pre-flood season (May to the third pentad of July) mostly occurs at 16:00-21:00 $\mathrm{h}$. When it comes to the major flood season (the fourth pentad of July to the second pentad of August), the precipitation peaks at 17:00-22:00 $\mathrm{h}$ and sub-peaks at 0:00-7:00 $\mathrm{h}$. In the post-flood season (the third pentad of August to September), the precipitation mostly occurs at night, with the peak occurring at 0:00-8:00 h.

(4) In the mountainous areas, the short-duration precipitation occurs most, accounting for $30 \%$ of the total rainy season rainfalls. The long-duration precipitation makes a larger contribution to the plains in the basin. The continuous precipitation is majorly encountered in the windward slopes of the Taihang Mountains and the Yanshan Mountains. From the perspective of the whole basin, the long-duration precipitation and continuous precipitation contribute more to the total rainy season rainfalls than the short-duration precipitation.

(5) Urbanization seems to have exerted a remarkable influence on local precipitation and intense rainfalls in large cities, leading to the larger warm-season mean precipitation and more frequent intense precipitation events in mid-summer and during the nighttime in large cities than in small cities. A major uncertainty in detecting the impact of urbanization may come from the possible influence of the under-catch effect of the gauge for the urban stations.

Author Contributions: Conceptualization, G.R. and J.G.; methodology, J.G. and G.R; software, J.G.; validation, G.R.; formal analysis, G.J. and H.H.; data curation, M.X.; writing—original draft preparation, J.G.; writing一review and editing, G.R.; visualization, H.H.; supervision, G.R.; funding acquisition, G.R. and J.G.

Funding: This study is supported by the National Key R\&D Program of China (No. 2018YFA0606302 and No.2018YFA0605603), and the Natural Science Foundation of China (NSFC) (41575003).

Conflicts of Interest: The authors declare no conflict of interest. The funders had no role in the design of the study; in the collection, analyses, or interpretation of data; in the writing of the manuscript, or in the decision to publish the results.

\section{References}

1. Xia, J.; Liu, C.Z.; Ren, G.Y. Opportunity and Challenge of the Climate Change Impact on the Water Resource of China. Adv. Earth Sci. 2011, 26. [CrossRef]

2. Liang, P.; He, J.H.; Chen, L.X.; Li, W. Anomalous Moisture Sources for the Severe Precipitation over North China during Summer. Plateau Meteorol. 2007, 26, 460-465. (In Chinese)

3. Liu, H.W.; Ding, Y.H. The Interdecadal Variability of Summer Precipitation over North China. J. Appl. Meteorol. Sci. 2011, 22, 129-137. (In Chinese)

4. Shi, Y.S.; Yao, X.X.; Yang, X.L.; Li, Z.T. Characteristic Analysis of Unusual Summer Precipitation in North China. Sci. Meteorol. Sin. 2008, 28, 377-383. (In Chinese) 
5. Yang, J.; Wang, Q.G.; Gong, Z.Q.; Guo-Lin, F. Dynamic Optimal Multi-Indexes Configuration for Estimating the Prediction Errors of Dynamical Climate Model in North China. Acta Phys. Sin. 2011, 60, 029204. (In Chinese)

6. Liu, Y.Y.; Ding, Y.H. Analysis and Numerical Simulation of the Teleconnection between Indian Summer Monsoon and Precipitation in North China. Acta Meteorol. Sin. 2008, 66, 789-799. (In Chinese)

7. Tang, X.; Qian, W.H.; Liang, P. Climate Feature of Boundary Belt for East Asian Summer Monsoon. Plateau Meteorol. 2006, 25, 375-381. (In Chinese)

8. Simmonds, I.; Bi, D.; Hope, P. Atmospheric Water Vapor Flux and Its Association with Rainfall over China in Summer. J. Clim. 1999, 12, 1353-1367. [CrossRef]

9. Tian, H.; Guo, P.W.; Lu, W.S. Characteristics of Vapor Inflow Corridors Related to Summer Rainfall in China and Impact Factors. J. Trop. Meteorol. 2004, 20, 401-408. (In Chinese)

10. Zhou, L.T. Characteristics of Interannual Variability of Summer Rainfall in North China. Trans. Atmos. Sci. 2009, 32, 412-423. (In Chinese)

11. Wang, Z.G.; Luo, Y.Z.; Liu, C.M.; Xia, J.; Zhang, M.H. Spatial and Temporal Variations of Precipitation in Haihe River Basin, China: Six Decades of Measurements. Hydrol. Process. 2011, 25, 2916-2923. [CrossRef]

12. Bao, Z.X.; Zhang, J.Y.; Wang, G.Q.; Fu, G.B.; He, R.M.; Yan, X.L.; Jin, J.L.; Liu, Y.L.; Zhang, A.J. Attribution for Decreasing Stream Flow of the Haihe River Basin, Northern China: Climate Variability or Human Activities? J. Hydrol. 2012, 460-461, 117-129. [CrossRef]

13. Liu, H.W.; Ding, Y.H. Analysis of Daily Precipitation Characteristics over North China during Rainy Seasons. Chin. J. Atmos. Sci. 2010, 34, 12-22. (In Chinese) [CrossRef]

14. Hao, L.S.; Min, J.Z.; Ding, Y.H. Analysis of Precipitation Events Changes and Causes for Rainstorm Events Reduction in North China. Chin. J. Geophys. 2011, 54, 1160-1167. (In Chinese) [CrossRef]

15. Li, J.; Yu, R.C.; Wang, J.J. Diurnal Variations of Summer Precipitation in Beijing. Chin. Sci. Bull. 2008, 53, $1933-1936$. [CrossRef]

16. Yang, P.; Xiao, Z.N.; Shi, W.J. Fine-Scale Characteristics of Rainfall in Beijing Urban Area Based on a High-Density Autonomous Weather Stations (AWS) Dataset. Chin. J. Atmos. Sci. 2017, 41, 475-489. (In Chinese)

17. Yu, R.C.; Zhou, T.J.; Xiong, A.Y.; Zhu, Y.J.; Li, J.M. Diurnal Variations of Summer Precipitation over Contiguous China. Geophys. Res. Lett. 2007, 34, L01704. [CrossRef]

18. Yu, R.C.; Li, J.; Yuan, W.H.; Chen, H.M. Changes in Characteristics of Late-Summer Precipitation over Eastern China in the Past 40 Years Revealed by Hourly Precipitation Data. J. Clim. 2010, 23, 3390-3396. [CrossRef]

19. Zhou, T.J.; Yu, R.C.; Chen, H.M.; Dai, A.G.; Pan, Y. Summer Precipitation Frequency, Intensity, and Diurnal Cycle over China: A Comparison of Satellite Data with Rain Gauge Observations. J. Clim. 2008, 21, 3997-4010. [CrossRef]

20. Yuan, W.H.; Yu, R.C.; Fu, Y.F. Study of Different Diurnal Variations of Summer Long-Duration Rainfall Between the Southern and Northern Parts of the Huai River. Chin. J. Geophys. 2014, 57, 752-759. (In Chinese) [CrossRef]

21. Han, H.; Wu, H.M.; Huang, A.N. Temporal and Spatial Distributions of the Diurnal Cycle of Summer Precipitation Over North China. Chin. J. Atmos. Sci. 2017, 41, 263-274. (In Chinese) [CrossRef]

22. Yu, R.C.; Xu, Y.P.; Zhou, T.J.; Li, J. Relation between Rainfall Duration and Diurnal Variation in the Rainy Season Precipitation over Central Eastern China. Geophys. Res. Lett. 2007, 34, L13703. [CrossRef]

23. Yin, S.Q.; Gao, G.; Li, W.J.; Chen, D.L.; Hao, L.S. Long-Term Precipitation Change by Hourly Data in Haihe River Basin during 1961-2004. Sci. China Earth Sci. 2011, 54, 1576-1585. (In Chinese) [CrossRef]

24. Zheng, Z.F.; Gao, H.; Wang, Z.W.; Li, Q.C. Analysis on Spatial Distribution of Precipitation in Beijing and Its City Effect. Plateau Meteorol. 2014, 33, 522-529. (In Chinese)

25. Fan, G.Z.; Lyu, S.H. Numerical Simulation Study for the Effect of Terrain on North China Summer Precipitation. Plateau Meteorol. 1999, 18, 659-667. (In Chinese)

26. Zhu, L.; Liu, Y.X.; Zuo, H.C.; Xiang, W.G.; Gong, Q.; Yu, H.S.; Lin, N.; Cao, H.; Gu, Z.Q. Water Vapor Transport Characteristics over the Haihe River Basin. Adv. Clim. Change Res. 2011, 7, 184-188. (In Chinese)

27. Zhou, X.X.; Ding, Y.H.; Wang, P.X. Features of Moisture Transport Associated with the Precipitation over North China during July-August. Chin. J. Atmos. Sci. 2008, 32, 345-357. (In Chinese)

28. Ma, J.J.; Gao, X.Q. The Transportation Paths of Water Vapor and Its Relation to Climate Change over North China. Plateau Meteorol. 2008, 25, 893-899. (In Chinese) 
29. Ye, M.; Wu, Y.P.; Zhou, J.; Wu, H.; Tu, G. Objective Quantification of the Water Vapor Path Influencing Precipitation in North China in Summer. Acta Phys. Sin. 2014, 63, 129201. (In Chinese)

30. Yu, R.C.; Li, J.; Chen, H.M.; Yuan, W.H. Progress in studies of the precipitation diurnal variation over contiguous China. Acta Meteorol. Sin. 2014, 72, 948-968. [CrossRef]

31. He, H.; Zhang, F. Diurnal Variations of Warm-Season Precipitation Over Northern China. Mon. Weather Rev. 2010, 138, 1017-1025. [CrossRef]

32. Wu, Z.H.; Chen, M.X. Climatic Analysis of Summer (JJA) Short-Period Precipitation in Beijing-Tianjin-Hebei Area. Chin. J. Atmos. Sci. 1993, 17, 268-273. (In Chinese)

33. Yang, P.; Ren, G.Y.; Hou, W.; Liu, W.D. Spatial and Diurnal Characteristics of Summer Rainfall over Beijing Municipality Based on a High-Density AWS Dataset. Int. J. Climatol. 2013, 33, 2769-2780. [CrossRef]

34. Yang, P.; Ren, G.Y.; Yan, P.C. Evidence for Strong Association of Short-Duration Intense Rainfall with Urbanization in Beijing Urban Area. J. Clim. 2017. [CrossRef]

35. Zhang, L.J.; Hu, T.J.; Hu, F.; Li, L.; Xuan, C.Y. Comparison of Summer Precipitation Evolution over the Last 30 Years between Urban and Rural Region of Beijing. Clim. Environ. Res. 2009, 14, 63-68. (In Chinese)

36. Ren, G.Y.; Ren, Y.Y.; Zhan, Y.J.; Sun, X.B.; Liu, Y.J.; Chen, Y.; Wang, T. Spatial and Temporal Patterns of Precipitation Variability over Mainland China: III: Causes for Recent Trends. Adv. Water Sci. 2016, 27, 327-348. (In Chinese)

37. Zheng, Z.F.; Ren, G.Y. Effects of Gauge Under-Catch on Precipitation Observation and Long-Term Trend Estimates in Beijing Area. Adv. Water Sci. 2017, 28, 662-670. (In Chinese)

38. Ren, G.Y.; Wang, T.; Guo, J.; Hao, Z.X.; Zhan, Y.J. Characteristics of Precipitation Variations in Haihe River Basin in Modern Times. Adv. Sci. Technol. Water Res. 2015, 35, 103-110. (In Chinese) [CrossRef]

(C) 2019 by the authors. Licensee MDPI, Basel, Switzerland. This article is an open access article distributed under the terms and conditions of the Creative Commons Attribution (CC BY) license (http://creativecommons.org/licenses/by/4.0/). 